Article

\title{
Increased Placental Cell Senescence and Oxidative Stress in Women with Pre-Eclampsia and Normotensive Post-Term Pregnancies
}

\author{
Paula J. Scaife ${ }^{1}$, Amy Simpson ${ }^{2}$, Lesia O. Kurlak ${ }^{3}$, Louise V. Briggs ${ }^{4}$, David S. Gardner ${ }^{3}$, \\ Fiona Broughton Pipkin ${ }^{2}$, Carolyn J. P. Jones ${ }^{5} \mathbb{D}$ and Hiten D. Mistry ${ }^{6, *}$ \\ 1 Clinical, Metabolic and Molecular Physiology Research Group, University of Nottingham, \\ Nottingham NG7 2RD, UK; paula.scaife@nottingham.ac.uk \\ 2 Department of Obstetrics \& Gynaecology, University of Nottingham, Nottingham NG7 2RD, UK; \\ amy.e.simpson98@gmail.com (A.S.); Fiona.broughton_pipkin@nottingham.ac.uk (F.B.P.) \\ 3 School of Veterinary Medicine and Science, University of Nottingham, Nottingham NG7 2RD, UK; \\ lesia.kurlak@nottingham.ac.uk (L.O.K.); David.gardner@nottingham.ac.uk (D.S.G.) \\ 4 School of Engineering, University of Nottingham, Nottingham NG7 2RD, UK; \\ louise.briggs@nottingham.ac.uk \\ 5 Maternal \& Fetal Health Research Centre, Manchester Academic Health Science Centre, University of \\ Manchester, Manchester M13 9PL, UK; carolyn.jones@manchester.ac.uk \\ 6 Department of Women and Children's Health, School of Life Course Sciences, King's College London, \\ London SE5 9NU, UK \\ check for \\ * Correspondence: hiten.mistry@kcl.ac.uk
}

updates

Citation: Scaife, P.J.; Simpson, A.; Kurlak, L.O.; Briggs, L.V.; Gardner, D.S.; Broughton Pipkin, F.; Jones,

C.J.P.; Mistry, H.D. Increased

Placental Cell Senescence and Oxidative Stress in Women with Pre-Eclampsia and Normotensive Post-Term Pregnancies. Int. J. Mol. Sci. 2021, 22, 7295. https://doi.org/ $10.3390 /$ ijms 22147295

Academic Editor: Jerome F. Strauss III

Received: 3 June 2021

Accepted: 2 July 2021

Published: 7 July 2021

Publisher's Note: MDPI stays neutral with regard to jurisdictional claims in published maps and institutional affiliations.

Copyright: (c) 2021 by the authors. Licensee MDPI, Basel, Switzerland. This article is an open access article distributed under the terms and conditions of the Creative Commons Attribution (CC BY) license (https:// creativecommons.org/licenses/by/ $4.0 /)$

\begin{abstract}
Up to $11 \%$ of pregnancies extend to post-term with adverse obstetric events linked to pregnancies over 42 weeks. Oxidative stress and senescence (cells stop growing and dividing by irreversibly arresting their cell cycle and gradually ageing) can result in diminished cell function. There are no detailed studies of placental cell senescence markers across a range of gestational ages, although increased levels have been linked to pre-eclampsia before full term. This study aimed to determine placental senescence and oxidative markers across a range of gestational ages in women with uncomplicated pregnancies and those with a diagnosis of pre-eclampsia. Placentae were obtained from 37 women with uncomplicated pregnancies of 37-42 weeks and from 13 cases of pre-eclampsia of $31^{+2}-41^{+2}$ weeks. The expression of markers of senescence, oxidative stress, and antioxidant defence (tumour suppressor protein p16 ${ }^{\mathrm{INK} 4 \mathrm{a}}$, kinase inhibitor p21, interleukin-6 (IL-6), NADPH oxidase 4 (NOX4), glutathione peroxidases 1, 3, and 4 (GPx1, GPx3, and GPx4), placental growth factor (PlGF), and soluble fms-like tyrosine kinase-1 (sFlt-1)) genes was measured (quantitative realtime PCR). Protein abundance of p16 ${ }^{\text {INK4a }}$, IL-6, NOX4, 8-hydroxy-2'-deoxy-guanosine (8-OHdG), and PIGF was assessed by immunocytochemistry. Placental NOX4 protein was higher in post-term than term deliveries and further increased by pre-eclampsia ( $p<0.05$ for all). P21 expression was higher in post-term placentae $(p=0.012)$ and in pre-eclampsia $(p=0.04)$, compared to term. Placental $\mathrm{P} 16^{\mathrm{INK} 4 \mathrm{a}}$ protein expression was increased post-term, compared to term $(p=0.01)$. In normotensive women, gestational age at delivery was negatively associated with GPx4 and PIGF (mRNA and protein) ( $p<0.05$ for all), whereas a positive correlation was seen with placental P21, NOX4, and P16 ${ }^{\text {INK4a }}(p<0.05$ for all) expression. Markers of placental oxidative stress and senescence appear to increase as gestational age increases, with antioxidant defences diminishing concomitantly. These observations increase our understanding of placental health and may contribute to assessment of the optimal gestational age for delivery.
\end{abstract}

Keywords: hypertension in pregnancy; angiogenesis; endothelial function; oxidative stress; antioxidants; post-maturity; senescence 


\section{Introduction}

The human placenta stops growing at $\sim 90 \%$ of full term ( 36 weeks of gestation), unlike that of other mammalian species, but the fetus continues to grow, which would presumably "stress" even a normal placenta. This feature is assumed to have evolved in parallel with upright posture and the necessary development of a very muscular uterus, delaying delivery. Ageing is a process that causes a deterioration in function at the cellular, tissue, and organ level, leading to individuals being more susceptible to disease. Short chromosomal telomeres, as well as the partial or complete insufficiency of the telomerase enzyme, have been linked to diseases caused by ageing [1]. Telomeres are protective caps made of nucleoprotein molecules located at the end of chromosomes and are necessary for protection against breaks at DNA ends, fusion of chromosome ends, and chromosome degradation [1]. Telomeres are shortened with each cell division. The rate at which this occurs is accelerated by certain stressors, such as oxidative stress [1]. Eventually, telomeres reach a dangerously short length, which initiates the process of cellular senescence, through which cells irreversibly stop growing and dividing by arresting their cell cycle and gradually ageing (becoming 'senescent') [2,3].

Prolonged pregnancy (also known as post-term pregnancy), is defined by the World Health Organisation as "the end of gestation at $\geq 42$ completed weeks of gestation, measured from the first day of the last menstrual period and based on a 28 day cycle" [4]. Adverse obstetric events have been linked with pregnancies that last longer than 42 weeks, including an increased frequency of foetal death and raised risk of foetal malnutrition, intrauterine foetal hypoxia, irregular nonstress tests, respiratory distress, oligohydramnios, delivery via Caesarean section, and stillbirth [5,6]. Furthermore, long-term health problems in the child have also been associated with pregnancies extending over 42 weeks [5].

In the developed world, up to $11 \%$ of pregnancies extend to post-term. However, this figure varies significantly between different countries with further disparity between low- and middle-income countries [5]. In the UK, a woman who has not spontaneously delivered by the start of 41 weeks is offered an induction of labour. The induction is performed between $41^{+0}$ and $42^{+0}$ weeks to avoid the associated risks of prolonged pregnancy [7].

The main risk factors associated with prolonged pregnancy are genetic, the mother having been born post-term herself, previous history of prolonged pregnancy, primiparity, and obesity [8]. Moreover, a Swedish study reported that one-quarter of the risk arises from the fetal genetic background, and another quarter arises from the mother [9].

Some of the signs associated with prolonged pregnancy are reduced fetal movements, a reduced volume of amniotic fluid, and meconium-stained amniotic fluid after the membranes have ruptured [10]. A seminal study conducted by Jones and Fox in 1978 investigated the structural changes in placentae after prolonged pregnancy and revealed that most of these placentae show morphological irregularities. A possible decline in trophoblastic cell function was postulated [11].

A study by Maiti et al. concluded that placental cells start to age dramatically from 37 weeks of gestation, with oxidative stress rising as gestational age increases [12]. Other studies suggest that premature placental ageing may contribute to placental dysfunction. This could be the cause of many placenta-related pathologies, such as pre-eclampsia [13], a multisystem disorder affecting up to $5 \%$ of pregnant women. It is one of the leading causes of maternal and perinatal mortality and morbidity, especially when it occurs before 34 weeks of gestation [14]. It is characterised by de novo hypertension together with evidence of endothelial cell damage and/or significant proteinuria in the absence of urinary tract infection [15]. Pre-eclampsia is associated with shallow placentation, inadequate remodelling of the uterine vasculature, and consequent oxidative stress; antioxidant defences are inadequate, and the synthesis of a variety of angiogenic and growth factors is perturbed [16].

Senescence stressors ultimately activate the P53 and/or cyclin-dependent kinase inhibitor 2A (P16 ${ }^{\text {INK4a }}$ ) pathways and secondary induction of cyclin-dependent kinase inhibitor (P21) [2]. Furthermore, interleukin-6 (IL-6) depletion is correlated with reduced 
formation of senescence-associated heterochromatin foci (SAHF) and, thus, can also be used as a surrogate marker of senescence [17].

In summary, oxidative stress in combination with cell senescence can cause extensive tissue damage, leading to accelerated cellular ageing. We hypothesised that extended, 'postterm' pregnancies and gestational disease such as pre-eclampsia both increase oxidative stress and cell senescence in placentae, relative to healthy term controls. To investigate this, we examined the mRNA expression and protein abundance of a panel of markers of cell senescence (P16 $6^{\mathrm{INK} 4 \alpha}, \mathrm{P} 21$, and IL-6), oxidative stress (NADPH oxidase 4 (NOX4), 8-Oxo-2'-deoxyguanosine (8-OHdg), a marker of DNA modification), antioxidant defence (glutathione peroxidases (GPx)), and placental function (PlGF and sFlt-1) in normotensive control and post-term placenta, as well as from women with pre-eclampsia.

\section{Results}

\subsection{Participants}

Baseline demographic and pregnancy outcome data are presented in Table 1. As can be seen, by definition, women who had pre-eclampsia had significantly higher blood pressures $(p<0.05)$ and significant proteinuria. They also delivered earlier, and their babies' birthweights were lower. Overall, the groups were matched for maternal age, BMI, and parity.

Table 1. Participant demographics and pregnancy outcome data.

\begin{tabular}{|c|c|c|c|}
\hline Parameter & $\begin{array}{c}\text { Term } \\
37-39^{+6} \\
(n=26)\end{array}$ & $\begin{array}{c}\text { Post-Term } \\
41-42 \\
(n=11)\end{array}$ & $\begin{array}{l}\text { Pre-Eclampsia } \\
\quad(n=13)\end{array}$ \\
\hline Age at booking (year) & $31 \pm 6.0$ & $31 \pm 6.4$ & $34 \pm 3.8$ \\
\hline BMI at booking $\left(\mathrm{kg} / \mathrm{m}^{2}\right)$ & $26[23,32]$ & $27[26,31]$ & $30[26,31]$ \\
\hline Nulliparous, $n(\%)$ & $10(38)$ & $5(45)$ & $8(62)$ \\
\hline Smoking, $n(\%)$ & $5(19)$ & $3(27)$ & $1(8)$ \\
\hline Systolic blood pressure (mmHg) & $110 \pm 10.6^{c}$ & $118 \pm 5.1^{c}$ & $158 \pm 12.3^{c}$ \\
\hline $\begin{array}{l}\text { Diastolic blood pressure } \\
(\mathrm{mmHg})\end{array}$ & $77 \pm 7.8^{\mathrm{c}}$ & $75 \pm 6.0^{\mathrm{c}}$ & $97 \pm 6.8^{c}$ \\
\hline Proteinuria & - & - & $1.0[0.4,1.4]$ \\
\hline $\begin{array}{l}\text { Gestational age at delivery } \\
\text { (weeks) }\end{array}$ & $39.4(36.3-40.6)^{a, c}$ & $41.3(41.0-42)^{\mathrm{a}, \mathrm{b}}$ & $37.2(31.1-41.1)^{b, c}$ \\
\hline Birth weight (g) & $3533 \pm 378^{a}$ & $3873 \pm 384^{b}$ & $2741 \pm 1073.7^{\mathrm{a}, \mathrm{b}}$ \\
\hline Birthweight centile & $74[47,94]$ & $86[65,94]$ & $48[26,78]$ \\
\hline Placental weight $(\mathrm{g})$ & $624 \pm 133.6$ & $696 \pm 92.6^{b}$ & $539 \pm 182.9^{b}$ \\
\hline $\begin{array}{l}\text { Baby gender, female } \\
n(\%)\end{array}$ & $14(54)$ & $5(45)$ & $8(62)$ \\
\hline $\begin{array}{l}\text { Caesarean Section } \\
n(\%)\end{array}$ & $19(73)$ & $11(73)$ & $8(77)$ \\
\hline
\end{tabular}

$\overline{\mathrm{abc}} p<0.05$ between the respective groups. Data are presented as mean $\pm \mathrm{SD}$, median [IQR], or median (range) for gestational age at delivery, depending on distribution or $n(\%)$. BMI: body mass index. Birthweight centiles calculated using INTERGROWTH 21 (https:/ /intergrowth21.tghn.org/standards-tools/; accessed on 25 May 2021).

\subsection{Gene Expression}

Considering markers of oxidative stress, expression of NOX4 was present in all samples (Figure 1A). NOX4 expression was increased post-term, compared to placentae from term deliveries $(p=0.013)$. For all GPxs, no differences were observed between groups ( $p>0.05$ for all), although there was a trend towards lower GPx4 expression in both post-term and pre-eclampsia groups. When further sub-grouped by gestational age, we found significantly higher GPx4 gene expression in the 37-39+0 -week placentae (median [IQR]: 17,765 [13,366, 25,101], normalised copy number) compared to the $40-40^{+6}$-week $(8729[2992,13,823] ; p<0.01)$ and 41-42-week placentae $(5739.1[2160,18,130] ; p=0.04)$, as well as in pre-eclampsia $(p=0.04)$. 
All markers of senescence were expressed (Figure 1E-G) in every group. Placental P21 expression was raised in post-term deliveries $(p=0.012)$, as well as in women with preeclampsia $(p=0.04)$, compared to term samples. For IL-6, women with pre-eclampsia had a higher placental expression compared to both term $(p=0.031)$ and post-term $(p=0.008)$; no differences were seen between term and post-term samples $(p>0.05)$. No differences were observed between groups for $\mathrm{P} 16^{\mathrm{INK} 4 \alpha}$.

We also examined expression of the placental functional markers, PlGF and sFlt-1 (Figure 1H,I). PlGF expression was lower in placentae from women with pre-eclampsia, compared to term $(p=0.008)$, but not post-term samples $(p>0.05)$; smaller differences between term and post-term expression did not reach statistical significance $(p=0.08)$. No differences were seen between groups for sFlt- 1 expression $(p>0.05)$.

Lastly, when considering any impact of gestational age at delivery in only the normotensive women, negative associations were observed with placental GPx4 $(r=-0.405$; $p=0.012)$ and PlGF $(r=-0.388 ; p=0.021)$, whereas a positive correlation was seen with P21 $(r=0.324 ; p=0.044)$.

A

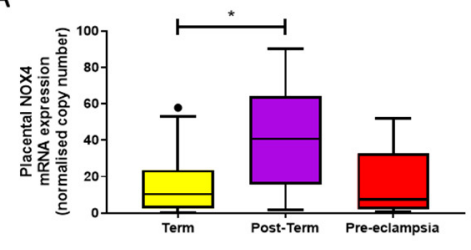

D

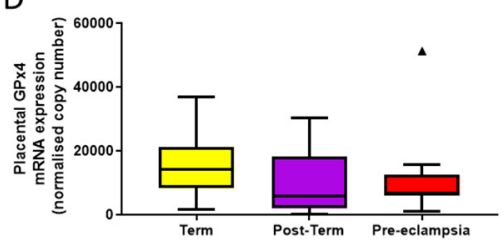

G

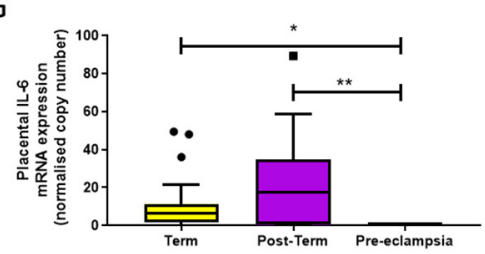

B

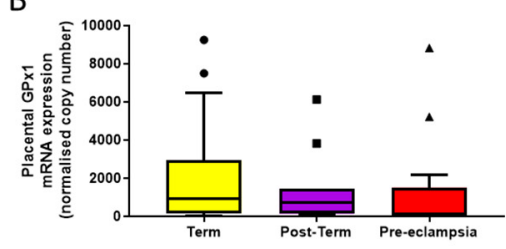

$\mathrm{E}$

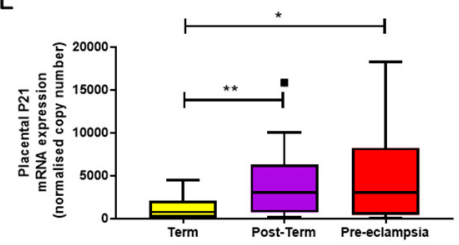

$\mathrm{H}$

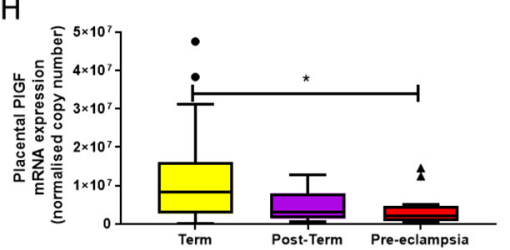

C

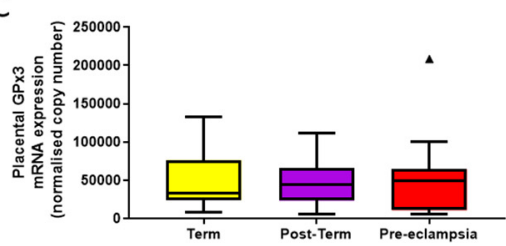

$\mathrm{F}$
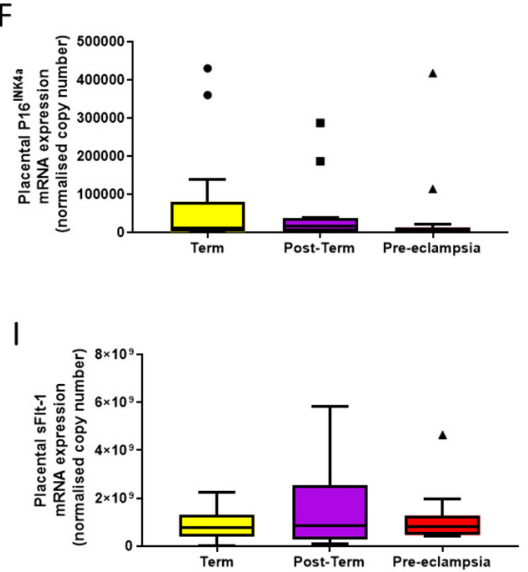

Figure 1. mRNA expression assessed by quantitative reverse-transcription PCR of (A) NADPH oxidase (NOX4), (B-D) glutathione peroxidases 1, 3, and 4 (GPx1, 3, and 4), respectively, (E) cyclin-dependent kinase inhibitor (P21), (F) cyclindependent kinase inhibitor 2A (P16 $\left.{ }^{\mathrm{INK} 4 \alpha}\right),(\mathrm{G})$ interleukin-6 (IL-6), (H) placental growth factor (PIGF), and (I) soluble fms-like tyrosine kinase-1 (sFlt-1) in placentae from term normotensive (37-40 + 6 weeks; $n=26)$, post-term normotensive (41-42 weeks; $n=11)$, and women who had pre-eclampsia $(n=13)$. Data are presented as median [IQR]; ${ }^{*} p<0.05$, ** $p<0.005$.

\subsection{Protein Expression}

NOX4 protein expression was confirmed in all placental samples analysed, with staining localised within nuclei and syncytiotrophoblast (Figure 2A). As with gene expression, NOX4 protein expression was higher in both post-term $(0.95[0.79,0.97] ; p=0.017)$ and pre-eclampsia samples $(0.94$ [0.92, 0.96]; $p<0.0001$; Figure 2A), compared to term samples (median [IQR]: 0.80 [0.77, 0.90] positivity), with more uniform, high expression observed in pre-eclampsia $(p>0.05)$. Placental expression of $8-\mathrm{OHdG}$ was localised mainly within the nuclei with some weak cytoplasmic staining (Figure 2B) and was highest in women with pre-eclampsia (median [IQR]: 0.77 [0.72, 0.83] positivity), compared to both term 
$(0.68[0.61,0.76] ; p=0.015)$ and post-term $(0.70[0.63,0.76] ; p=0.021)$ samples (Figure 2B); similar expression was observed between term and post-term $(p>0.05)$.

A
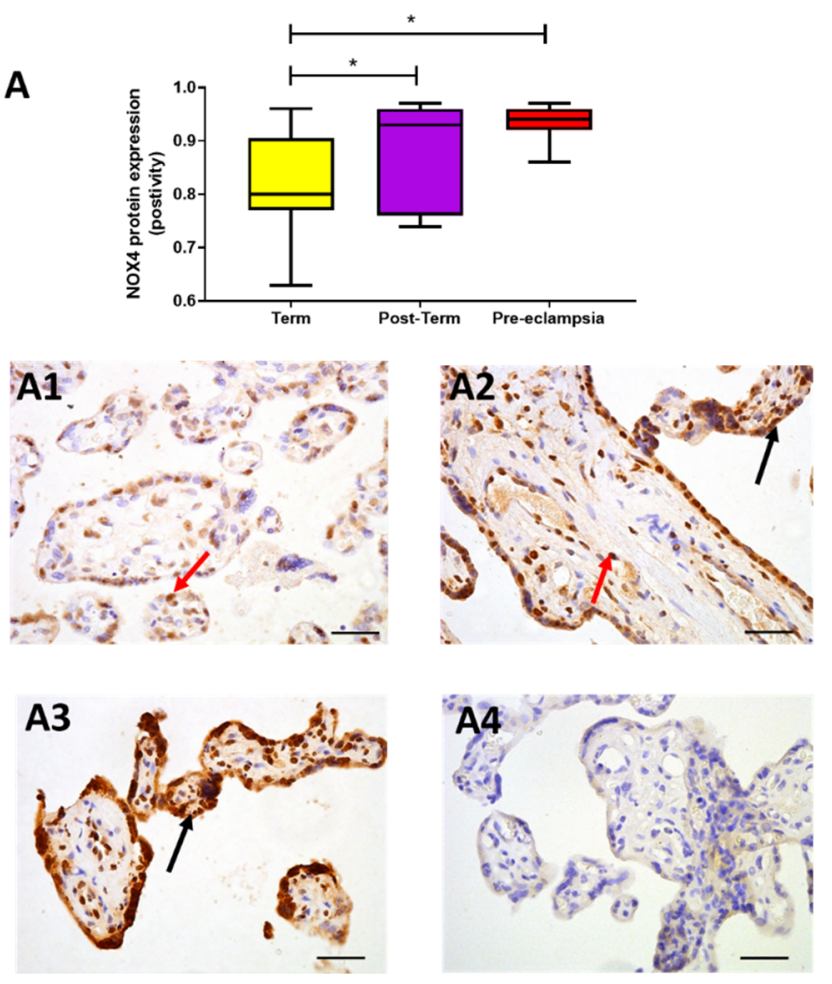

B

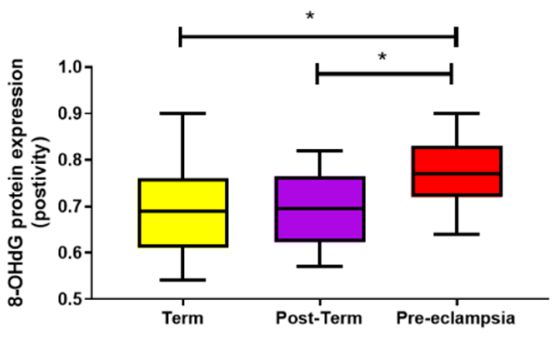

B1
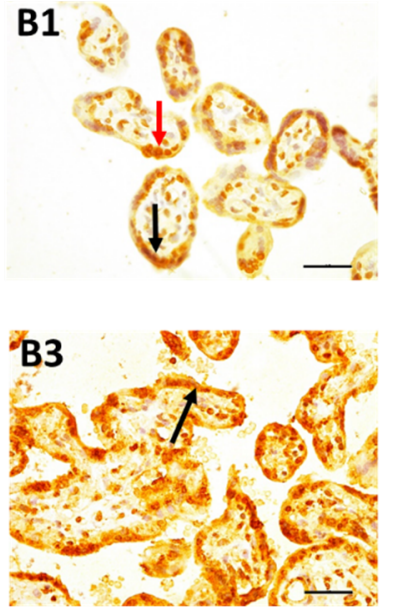

B2
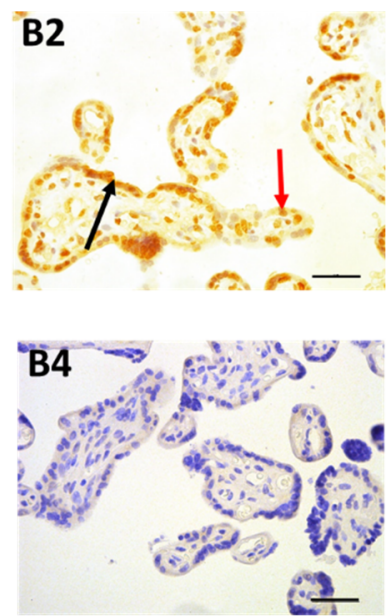

Figure 2. Protein expression assessed by immunohistochemistry. (A) NADPH oxidase (NOX4) and (B) 8-hydroxy-2' -deoxyguanosine $(8-\mathrm{OHdG})$ in placentae from term normotensive $(37-40+6$ weeks; $n=26)$, post-term normotensive (41-42 weeks; $n=11)$, and women who had pre-eclampsia, delivered at $31+2$ to $41+2$ weeks gestation $(n=13)$. Data are presented as median [IQR]; * $p<0.05$. Photomicrographs show typical examples of immunostaining in (A1,B1) term, (A2,B2) post-term, (A3,B3) pre-eclampsia, and (A4,B4) IgG negative control. Positive protein expression appears brown and is localised mainly to the syncytiotrophoblast (black arrows) but is also evident in the nuclei (red arrows); scale bar $=100 \mu \mathrm{m}$.

P16 ${ }^{\text {INK4a }}$ expression differed between groups $(p=0.036)$. Expression was higher in post-term $(0.22[0.20,0.32])$ compared to term $(0.13[0.09,0.23] ; p=0.011)$ and was found mainly in the endothelium; however, placentae from women with pre-eclampsia exhibited similar expression $(0.20$ [0.09, 0.40]; $p>0.05$; Figure 3A). IL-6 localised mainly to the endothelium of the villi and overall expression was low; expression did not differ between groups ( $p>0.05$; Figure 3B). 

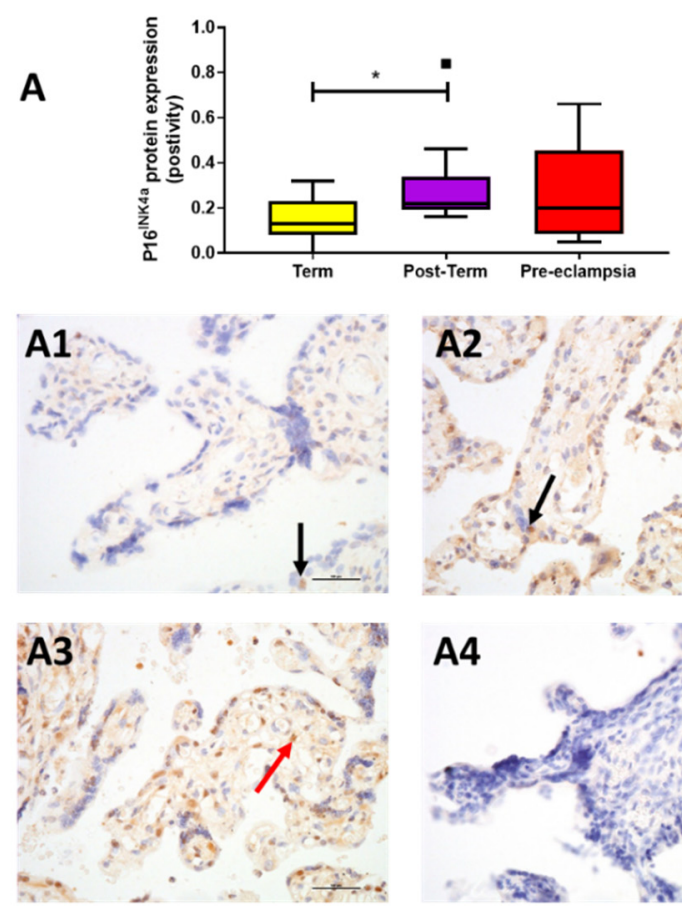

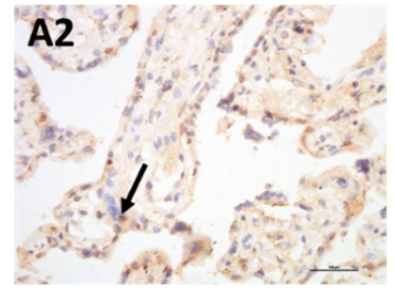

\section{A4}

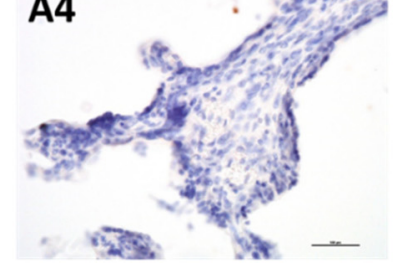

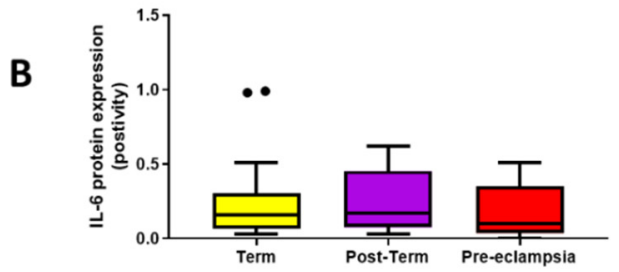

B1
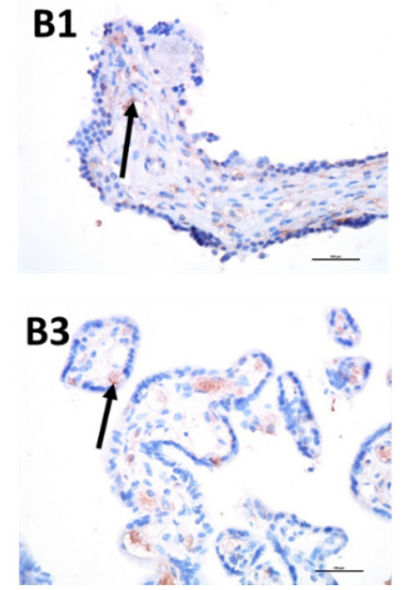
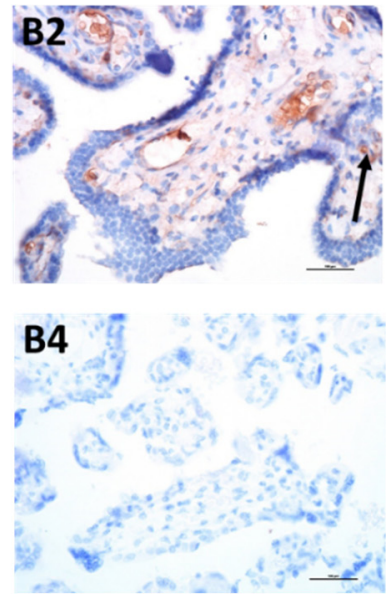

Figure 3. Protein expression assessed by immunohistochemistry. (A) P16 ${ }^{\mathrm{INK} 4 \mathrm{a}}$ and (B) interleukin-6 (IL-6) in placentae from term normotensive (37-40 + 6 weeks; $n=26)$, post-term normotensive (41-42 weeks; $n=11)$, and women who had pre-eclampsia $(n=13)$. Data are presented as median $[\mathrm{IQR}] ;{ }^{*} p<0.05$. Photomicrographs show typical examples of immunostaining in (A1,B1) term, (A2,B2) post-term, (A3,B3) pre-eclampsia and (A4,B4) IgG negative control. Positive protein expression of $\mathrm{P} 16^{\mathrm{INK} 4 \mathrm{a}}$ appears brown and is localised mainly to the syncytiotrophoblast (black arrow) with some stromal cell staining (red arrow); that of interleukin 6 is found mainly in endothelial cells (arrows); scale bar $=100 \mu \mathrm{m}$.

PlGF expression was weak and localised to the syncytiotrophoblast layer (Figure 4) and, although levels did not differ statistically between groups $(p>0.05)$, there was a trend towards lower expression in post-term $(0.0024[0.0013,0.023])$ and placentae from women with pre-eclampsia $(0.0069[0.0039,0.019])$, compared to term $(0.0073[0.0026,0.045])$ (Figure 4).

Again, when considering the impact of gestational age at delivery in only the normotensive women, a positive association was evident with placental P16 ${ }^{\mathrm{INK} 4 \mathrm{a}}$ expression $(r=0.331 ; p=0.04$; Figure 5A). In contrast, a negative correlation was seen with PlGF expression $(r=-0.367 ; p=0.046$; Figure $5 \mathrm{~B})$. In addition, placental expression of P16 ${ }^{\mathrm{INK} 4 \mathrm{a}}$ and NOX4 were positively correlated $(r=0.537 ; p=0.001$; Figure $5 \mathrm{C})$. 

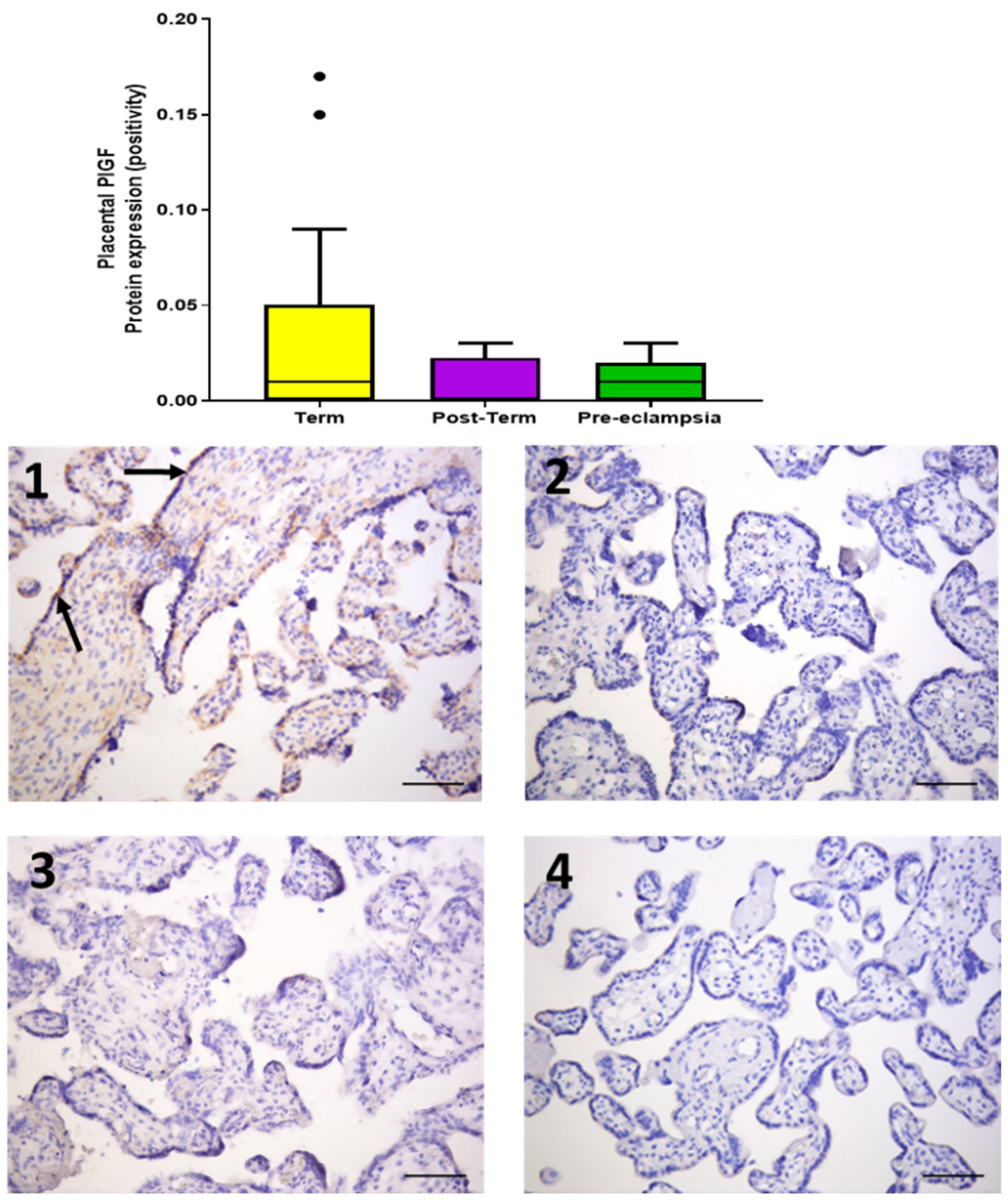

Figure 4. Protein expression of placental growth factor (PlGF) assessed by immunohistochemistry in placentae from term normotensive $(37-40+6$ weeks; $n=26)$, post-term normotensive (41-42 weeks; $n=11)$, and women who had pre-eclampsia $(n=13)$. Data are presented as median [IQR]. Photomicrographs show typical examples of immunostaining in (1) term, (2) post-term, (3) pre-eclampsia, and (4) IgG negative control. Positive protein expression is weak and appears brown, localised mainly to the syncytiotrophoblast (black arrows); scale bar $=100 \mu \mathrm{m}$. 
A

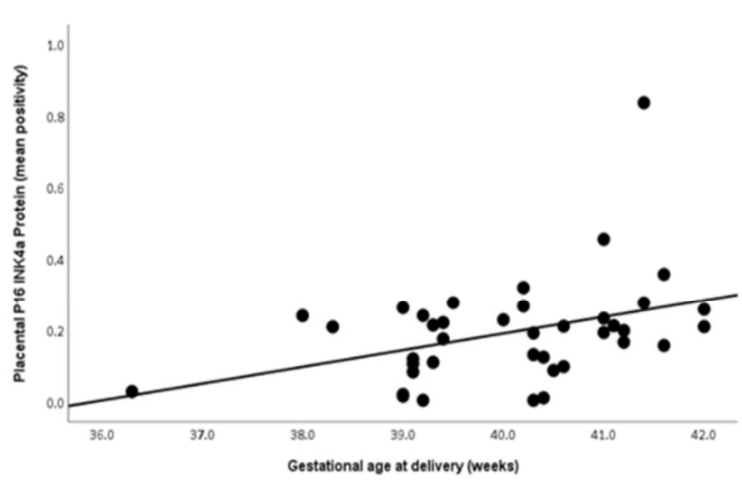

B

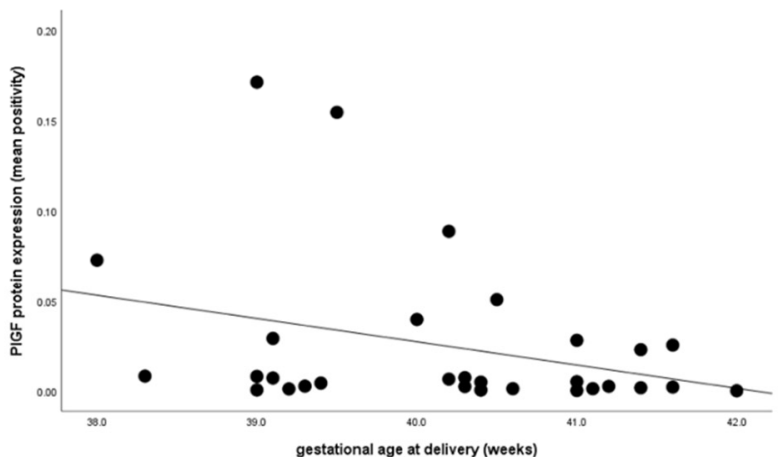

C

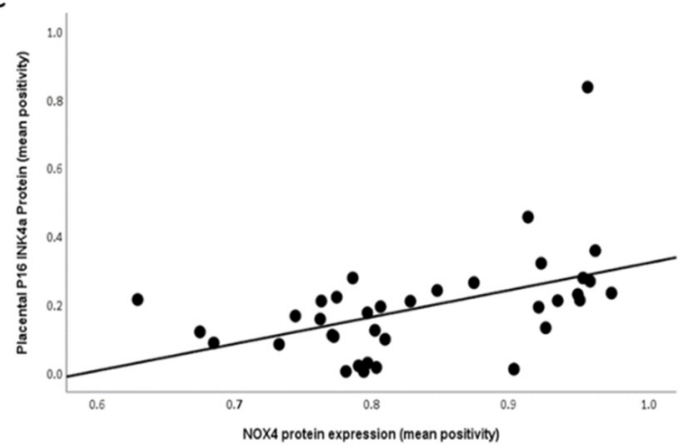

Figure 5. Scatter plot illustrations showing correlations between gestational age at delivery and (A) P16INK4a $(r=0.331$; $p=0.04$ ) and (B) placental growth factor (PlGF; $r=-0.367 ; p=0.046) ;(\mathbf{C})$ between P16 ${ }^{\mathrm{INK} 4 \mathrm{a}}$ and NADPH oxidase 4 (NOX4; $r=0.537 ; p=0.001)$ in normotensive samples only.

\section{Discussion}

Features of placental ageing may play a role in the morbidity associated with prolonged gestation. After 39 weeks of pregnancy, the fetal death rate rises fourfold $[18,19]$. Maiti et al. studied placentae from three groups: term ( 39 weeks), late term ( $>41$ weeks), and idiopathic stillbirths; they found increased aldehyde oxidase 1 expression (a mediator of placental ageing), DNA/RNA and lipid oxidation, lysosomes situated perinuclearly and basally as opposed to apically when localised with lysosome-associated membrane protein 2 (LAMP2), and bigger autophagosomes suggestive of inhibition of function in later-term placentae [12]. Towards the end of pregnancy and amplified during the postterm period, the foetal demands for oxygen and nutrients outstrip the placenta's ability to supply, thus leading to increased oxidative stress and subsequent deterioration of the placenta, including marked senescence [20].

We have now shown increased cell senescence and oxidative stress not only in placentae from normotensive women who delivered post term but also from women who developed pre-eclampsia, when compared to normotensive women delivering at term. The fact that increased gene and protein expression of NOX4, one of the sources of cellular reactive oxygen species (ROS), was evident in both post-term and pre-eclamptic groups implies that these placentae are under significant oxidative stress. Whilst this is well known in pre-eclampsia [21], this is the first detailed report in normotensive post-term placentae.

In this study, 8-OHdG protein expression was only raised in the placentae from women who had pre-eclampsia in concordance with others [13], reflecting oxidative DNA damage. However, one other study has shown increased 8-OHdG expression in postterm placentae, using a different technique, specifically, counting the number of positively stained nuclei [12]. Nevertheless, increased levels of oxidative stress cause damage to DNA, proteins, and lipids in placental tissue, which may manifest as another form of accelerated placental ageing. The antioxidant GPX genes also showed a trend towards reduced levels in the post-term and pre-eclamptic tissue. There were, however, no significant differences 
between groups in the protein expression of the cytokine IL-6, despite gene expression being raised in the pre-eclampsia group. A possible reason for this is that IL-6 is downstream of senescence, not an initiator of it [22]. Thus, placental senescence in post-term pregnancy does not activate this particular inflammatory cascade or has not been around long enough to do so.

In this study, increased protein expression of the senescence marker P16 ${ }^{\mathrm{INK} 4 \mathrm{a}}$ was observed in post-term and pre-eclamptic placental tissue. The $\mathrm{p} 16 / \mathrm{pRb}$ and $\mathrm{p} 53 / \mathrm{p} 21$ pathways are reported to be activated in various cell lines in response to stimuli that induce irreversible cellular senescence $[23,24]$. Cell fusion, an essential physiological process to establish and expand the syncytiotrophoblast, has been recognised to be a further trigger of cell senescence, and the syncytiotrophoblast features characteristics of senescent cells including the biomarker senescence-associated beta-galactosidase (SA- $\beta$-gal), together with high expression of the cyclin kinases inhibitors p16, p21, and p53 [25], which regulate cellcycle progression at $G_{1}$ and $S$ phase. It must be noted that syncytiotrophoblast senescence is a normal physiological phenomenon, which progresses as pregnancy advances [26]. However, there is increasing evidence to suggest that, when physiological senescence is accelerated, it results in placental and clinical pathology. Cindrova-Davies et al. reported placental P21 protein expression to be higher in post-term and pre-eclampsia samples [13]. Moreover, increased placental or trophoblast senescence has already been demonstrated in terms of telomere shortening, aggregation, or other measures of telomere dysfunction, both in pre-eclampsia and in normotensive women with foetal growth restriction [27-31].

Our data also demonstrated that mRNA and protein expressions of the proangiogenic growth factor PIGF were lower in placentae from women with pre-eclampsia and post-term samples, although the latter did not achieve statistical significance. It is known that pre-eclampsia is partly mediated by dysfunctional syncytiotrophoblast, and PIGF (as a marker for syncytiotrophoblast health) has appeared as a good marker for early-onset pre-eclampsia [32]. However, this is not the case in late-onset pre-eclampsia occurring towards term. Interestingly, in uncomplicated normotensive pregnancy, circulating PlGF concentrations rise steadily, peaking around 30 weeks, and then fall [32]. This suggests that the syncytiotrophoblast becomes increasingly stressed for the last 8-10 weeks of pregnancy [33] and possibly beyond. Further supporting data show that $\mathrm{pO}_{2}$ measurements of maternal intervillous and umbilical venous and arterial bloods decline in the third trimester, with slowing placental growth [34]. These data collectively suggest that normotensive women also have placentae with syncytiotrophoblast stress both at term and post-term [33].

When defining 'term' pregnancy according to the American College of Obstetricians and Gynaecologists, the neonatal outcome measures on delivery vary greatly between delivery at $37^{+0}$ and $42^{+0}$ weeks [35]; therefore, the importance of accurately establishing the gestational age cannot be overemphasised. Nonetheless, there are many countries in which mothers are unable to access ultrasound scans and do not have verifiable measurements of gestational age, meaning that the actual rate of post-term births in such countries may be higher than that officially recorded [5].

In this study we wished both to identify whether placentae from post-term pregnancies showed evidence of increasing senescence and to determine whether placentae from pre-eclamptic women showed accelerated senescence earlier in pregnancy. Both post-term pregnancy and pre-eclampsia are associated with increased risk of sudden fetal death, presumably consequent on placental failure. This is a preliminary study; hence, we chose to investigate well-established markers of several different aspects of senescence, rather than immediately performing gene-array studies. Future studies will require the use of RNA-seq as an unbiased approach to using tissues from different gestational stages and then test known genes, as well as novel genes, to further support our initial findings. Our data demonstrate that placental oxidative stress and senescence increase, in parallel with a reduction in PlGF expression, as normotensive pregnancy progresses, while antioxidant defences diminish as gestational age increases. These features become evident earlier in gestation in women with pre-eclampsia, suggesting accelerated senescence, probably 
secondary to their poor antioxidant status [13]. If these markers can be detected in the circulation, they may prove useful in screening for women with more severe problems of post-term pregnancy and pre-eclampsia.

\section{Materials and Methods}

\subsection{Cohort and Sample Collection}

The study population (Table 1) consisted of two groups of normotensive women: term $(n=26)$, with gestational age of $37-40^{+6}$ weeks, and post-term $(n=11)$, with gestational age of 41-42 weeks. The inclusion criteria comprised no maternal or pregnancy complications, live birth, singleton pregnancy, and delivery either vaginally or by Caesarean section. A third group consisted of women diagnosed with pre-eclampsia $(n=13)$ and delivered between $31^{+2}$ and $41^{+2}$ weeks. Pre-eclampsia was defined as systolic blood pressure of $\geq 140 / 90 \mathrm{mmHg}$ on two occasions and proteinuria $\geq 300 \mathrm{mg} / \mathrm{L}, 500 \mathrm{mg} /$ day, or $\geq 2+$ on a dipstick analysis of midstream urine after 20 weeks [36]. Detailed demographics and outcome data have previously been published [37]. The study was approved by the HRA-REC ethics committee of the University of Nottingham (REF: 15/EM/0523); written, informed consent to take part in the study was obtained from each participant.

Full-depth tissue biopsies were collected within 10 min of the placenta being delivered as previously described [37]. Samples were taken from the mid-point between the umbilical cord insertion and the periphery of the placenta, avoiding infarcts. One set of samples was snap-frozen and stored at $-80^{\circ} \mathrm{C}$ for RNA analysis. The other set was formalin-fixed and embedded in paraffin wax for immunohistochemistry.

4.2. RNA Extraction, cDNA Synthesis, and Quantitative Reverse-Transcription Polymerase Chain Reaction (RT-qPCR)

Total RNA was extracted from $100 \mathrm{mg}$ of placental tissue using QIAzol lysis reagent (Qiagen, UK) as previously described [38]. RNA (1 $\mu \mathrm{g})$ was reverse-transcribed using the QuantiTect Reverse Transcription kit (Qiagen, UK) in a Primus96 thermocycler (Peqlab Ltd., Southampton, UK). RT-qPCR was carried out using SYBR Green chemistry $(2 \times$ QuantiFast SYBR Green, Qiagen, UK) on an AB7500 Fast (Life Technologies, Cramlington, $\mathrm{UK}$ ) using primers to NADPH oxidase 4 (NOX4), glutathione peroxidase 1, 3, and 4 (GPX1, GPX3 GPX4), cyclin-dependent kinase inhibitor $2 A\left(P 16^{I N K 4 \alpha}\right)$, cyclin-dependent kinase inhibitor (P21), interleukin-6 (IL-6), placental growth factor (PlGF), and soluble fms-like tyrosine kinase-1 (a splice variant of VEGF receptor 1, sFlt-1; Table 2). Cycling conditions were as follows: a pre-PCR cycle was run for $15 \mathrm{~min}$ at $95{ }^{\circ} \mathrm{C}$ followed by 40 cycles of $95{ }^{\circ} \mathrm{C}$ for $10 \mathrm{~s}$ and $60{ }^{\circ} \mathrm{C}$ for $30 \mathrm{~s}$. Abundance data for the genes of interest were expressed as normalised copy number following normalisation using GeNORM (http:/ / medgen.ugent.be/ jvdesomp/ genorm/; accessed on 3 November 2018), with stably expressed reference genes [39] beta-2 microglobulin (B2M), tyrosine 3-monooxygenase/tryptophan 5-monooxygenase activation protein zeta (YWHAZ), and glyceraldehyde 3-phosphate dehydrogenase (GADPH) (Table 2).

Table 2. Details of primers used.

\begin{tabular}{|c|c|c|c|}
\hline Gene & $\begin{array}{l}\text { Accession } \\
\text { Number }\end{array}$ & Primers & $\begin{array}{l}\text { Length } \\
\text { (bp) }\end{array}$ \\
\hline Nox4 & NM_016931.3 & $\begin{array}{c}\text { 5'-TGAACTATGAGGTCAGCCTCTG-3' }^{\prime} \\
5^{\prime}-\mathrm{TCTCACGAATCTCCTCATGGT-3'}\end{array}$ & 107 \\
\hline GPx1 & NM_201397 & $\begin{array}{c}\text { 5'-CAGTCGGTGTATGCCTTCTCG-3' } \\
\text { 5'-GAGGGACGCCACATTCTCG-3' }\end{array}$ & 105 \\
\hline$G P x 3$ & NM_002084 & $\begin{array}{c}5^{\prime} \text {-GAGCTTGCACCATTCGGTCT-3' } \\
5^{\prime}-\text { GGGTAGGAAGGATCTCTGAGTTC-3' }\end{array}$ & 94 \\
\hline$G P x 4$ & NM_001039847 & $\begin{array}{c}5^{\prime} \text {-GAGGCAAGACCGAAGTAAACTAC-3' } \\
5^{\prime} \text {-CCGAACTGGTTACACGGGAA-3' }\end{array}$ & 100 \\
\hline
\end{tabular}


Table 2. Cont.

\begin{tabular}{|c|c|c|c|}
\hline Gene & $\begin{array}{l}\text { Accession } \\
\text { Number }\end{array}$ & Primers & $\begin{array}{l}\text { Length } \\
\text { (bp) }\end{array}$ \\
\hline$P 16^{I N K 4 a}$ & NM_000077.4 & $\begin{array}{c}5^{\prime}-\text { CTTCGGCTGACTGGCTGG-3' } \\
5^{\prime}-\text { TCATCATGACCTGGATCGGC-3' }\end{array}$ & 129 \\
\hline$P 21$ & NM_078467 & $\begin{array}{c}\text { 5'-TGTCCGTCAGAACCCATGC-3' } \\
\text { 5'-AAAGTCGAAGTTCCATCGCTC-3' }\end{array}$ & 139 \\
\hline$I L-6$ & NM_000600 & $\begin{array}{l}\text { 5'-ACTCACCTCTTCAGAACGAATTG-3' } \\
5^{\prime} \text {-CCATCTTTGGAAGGTTCAGGTTG-3' }\end{array}$ & 149 \\
\hline PlGF & NM_001207012 & $\begin{array}{c}5^{\prime}-\mathrm{GAACGGCTCGTCAGAGGTG-3'} \\
5^{\prime}-\mathrm{ACAGTGCAGATTCTCATCGCC}-3^{\prime}\end{array}$ & 187 \\
\hline sFlt-1 & NM_001159920 & $\begin{array}{c}\text { 5'-TTTGCCTGAAATGGTGAGTAAGG-3' } \\
5^{\prime} \text {-TGGTTTGCTTGAGCTGTGTTC-3' }\end{array}$ & 117 \\
\hline$B 2 M$ & NM_004048.2 & $\begin{array}{c}\text { 5'-CTTATGCACGCTTAACTATCTTAACAA-3' } \\
5^{\prime} \text {-TAGGAGGGCTGGCAACTTAG-3' }\end{array}$ & 127 \\
\hline YWHAZ & NM_001135702.1 & $\begin{array}{c}5^{\prime}-\text { ACTTTTGGTACATTGTGGCTTCAA-3' } \\
5^{\prime}-\text { CCGCCAGGACAAACCAGTAT-3' }\end{array}$ & 94 \\
\hline GAPDH & NM_002046.3 & $\begin{array}{l}\text { 5'-GGAAGCTTGTCATCAATGGAA-3' }^{\prime} \\
5^{\prime}-\text { TGGACTCCACGACGTACTCA-3' }\end{array}$ & 102 \\
\hline
\end{tabular}

\subsection{Immunohistochemical Staining}

Placental protein expression was assessed by immunohistochemistry as previously described [38], using antibodies to NOX4, 8-Oxo-2'-deoxyguanosine (8-OHdg), $\mathrm{P} 16^{\mathrm{INK} 4 \alpha}$, IL-6, and PlGF at concentrations detailed in Table 3. Immunoglobulin G (IgG) from the same host as the primary antibody was used as a negative control. All slides were assessed by the same observer, blinded to group. Quantification was performed as described previously [38], using the Positive Pixel Algorithm of Aperio ImageScope software; a visual check was also performed.

Table 3. Antibody details.

\begin{tabular}{ccc}
\hline Antigen & Suppler Information & Concentration $(\mu \mathrm{g} / \mathbf{m L})$ \\
\hline NOX4 & Abcam, rabbit monoclonal: ab133303 & 2.18 \\
8-0HdG & Abcam, mouse monoclonal: ab48508 & 12 \\
p16 ${ }^{\text {INK4 }}$ & Abcam, rabbit polyclonal: ab108349 & 0.7 \\
IL-6 & Abcam, mouse monoclonal: ab9324 & 10 \\
PlGF & Abcam, rabbit polyclonal: ab196666 & 10 \\
\hline
\end{tabular}

\subsection{Statistical Analysis}

All tests were performed using SPSS version 26 and GraphPad Prism version 8. Summary data are presented as means \pm standard deviation (SD) or median and interquartile range (IQR) as appropriate. The Kruskal-Wallis test, followed by Mann-Whitney U-test, was used for multiple group analysis. Student's $t$-tests or Mann-Whitney U-tests were applied depending on whether the data distribution was normal or skewed, as indicated by the Kolmogorov-Smirnov test. The null hypothesis was rejected when $p<0.05$.

Author Contributions: Conceptualization, P.J.S., L.O.K. and H.D.M.; data curation, A.S., L.V.B., D.S.G. and H.D.M.; formal analysis, L.O.K., F.B.P., C.J.P.J. and H.D.M.; funding acquisition, H.D.M.; investigation, P.J.S., L.O.K., L.V.B., F.B.P., C.J.P.J. and H.D.M.; methodology, P.J.S., A.S., D.S.G. and H.D.M.; writing—original draft, H.D.M.; writing—review and editing, P.J.S., A.S., L.O.K., L.V.B., D.S.G., F.B.P. and C.J.P.J. All authors read and agreed to the published version of the manuscript.

Funding: This work was produced by HDM under the terms of a BHF Basic Science Intermediate Basic Science Fellowship (FS/15/32/31604). 
Institutional Review Board Statement: The study was conducted according to the guidelines of the Declaration of Helsinki and approved by HRA-REC ethics committee of the University of Nottingham (REF: 15/EM/0523).

Informed Consent Statement: Signed, informed consent was obtained from all subjects involved in the study.

Data Availability Statement: Data is contained within the article and additional raw data can be obtained from the corresponding author on request.

Acknowledgments: We thank the women who participated in the study and the midwives/doctors whose support made this study possible. We thank Ceri Staley for help with the immunohistochemical staining of PIGF.

Conflicts of Interest: The authors declare no conflict of interest.

\section{References}

1. Sultana, Z.; Maiti, K.; Aitken, J.; Morris, J.; Dedman, L.; Smith, R. Oxidative stress, placental ageing-related pathologies and adverse pregnancy outcomes. Am. J. Reprod. Immunol. 2017, 77, e12653. [CrossRef]

2. van Deursen, J.M. The role of senescent cells in ageing. Nature 2014, 509, 439-446. [CrossRef]

3. Kumari, R.; Jat, P. Mechanisms of Cellular Senescence: Cell Cycle Arrest and Senescence Associated Secretory Phenotype. Front. Cell Dev. Biol. 2021, 9, 645593. [CrossRef]

4. WHO. Recommended definitions, terminology and format for statistical tables related to the perinatal period and use of a new certificate for cause of perinatal deaths. Modifications recommended by FIGO as amended October 14, 1976. Acta Obstet. Gynecol. Scand. 1977, 56, 247-253.

5. Ayyavoo, A.; Derraik, J.G.; Hofman, P.L.; Cutfield, W.S. Postterm births: Are prolonged pregnancies too long? J. Pediatrics 2014, 164, 647-651. [CrossRef]

6. Wennerholm, U.B.; Saltvedt, S.; Wessberg, A.; Alkmark, M.; Bergh, C.; Wendel, S.B.; Fadl, H.; Jonsson, M.; Ladfors, L.; Sengpiel, V.; et al. Induction of labour at 41 weeks versus expectant management and induction of labour at 42 weeks (SWEdish Post-term Induction Study, SWEPIS): Multicentre, open label, randomised, superiority trial. BMJ 2019, 367, 16131. [CrossRef]

7. NICE. Inducing Labour; NICE Public Health Guidance: London, UK, 2008.

8. Galal, M.; Symonds, I.; Murray, H.; Petraglia, F.; Smith, R. Postterm pregnancy. Facts Views Vis. Obgyn. $2012,4,175-187$.

9. Oberg, A.S.; Frisell, T.; Svensson, A.C.; Iliadou, A.N. Maternal and fetal genetic contributions to postterm birth: Familial clustering in a population-based sample of 475,429 Swedish births. Am. J. Epidemiol. 2013, 177, 531-537. [CrossRef]

10. Harding, M. Post-term Prenancy. In Patient; NICE: London, UK, 2016.

11. Jones, C.J.; Fox, H. Ultrastructure of the placenta in prolonged pregnancy. J. Pathol. 1978, 126, 173-179. [CrossRef]

12. Maiti, K.; Sultana, Z.; Aitken, R.J.; Morris, J.; Park, F.; Andrew, B.; Riley, S.C.; Smith, R. Evidence that fetal death is associated with placental aging. Am. J. Obstet. Gynecol. 2017, 217, 441.e1-441.e14. [CrossRef]

13. Cindrova-Davies, T.; Fogarty, N.M.E.; Jones, C.J.P.; Kingdom, J.; Burton, G.J. Evidence of oxidative stress-induced senescence in mature, post-mature and pathological human placentas. Placenta 2018, 68, 15-22. [CrossRef]

14. Steegers, E.A.; von Dadelszen, P.; Duvekot, J.J.; Pijnenborg, R. Pre-eclampsia. Lancet 2010, 376, 631-644. [CrossRef]

15. Brown, M.A.; Magee, L.A.; Kenny, L.C.; Karumanchi, S.A.; McCarthy, F.P.; Saito, S.; Hall, D.R.; Warren, C.E.; Adoyi, G.; Ishaku, S.; et al. The hypertensive disorders of pregnancy: ISSHP classification, diagnosis \& management recommendations for international practice. Pregnancy Hypertens 2018, 13, 291-310. [PubMed]

16. Ives, C.W.; Sinkey, R.; Rajapreyar, I.; Tita, A.T.N.; Oparil, S. Preeclampsia-Pathophysiology and Clinical Presentations: JACC State-of-the-Art Review. J. Am. Coll. Cardiol. 2020, 76, 1690-1702. [CrossRef] [PubMed]

17. Carnero, A. Markers of Cellular Senescence. In Cell Senescence Methods and Protocols; Galluzzi, L., Vitala, I., Kepp, O., Kroemer, G., Eds.; Humana Press: Totowa, NJ, USA, 2013.

18. Yudkin, P.L.; Wood, L.; Redman, C.W. Risk of unexplained stillbirth at different gestational ages. Lancet 1987, 1, 1192-1194. [CrossRef]

19. Ferrari, F.; Facchinetti, F.; Saade, G.; Menon, R. Placental telomere shortening in stillbirth: A sign of premature senescence? J. Matern. Fetal Neonatal Med. 2016, 29, 1283-1288. [CrossRef]

20. Smith, R.; Maiti, K.; Aitken, R.J. Unexplained antepartum stillbirth: A consequence of placental aging? Placenta 2013, 34, 310-313. [CrossRef]

21. Williams, P.J.; Mistry, H.D.; Innes, B.A.; Bulmer, J.N.; Broughton Pipkin, F. Expression of AT1R, AT2R and AT4R and their roles in extravillous trophoblast invasion in the human. Placenta 2010, 31, 448-455. [CrossRef]

22. Hirano, T. IL-6 in inflammation, autoimmunity and cancer. Int. Immunol. 2021, 33, 127-148. [CrossRef] [PubMed]

23. Hannan, K.M.; Brandenburger, Y.; Jenkins, A.; Sharkey, K.; Cavanaugh, A.; Rothblum, L.; Moss, T.; Poortinga, G.; McArthur, G.A.; Pearson, R.B.; et al. mTOR-dependent regulation of ribosomal gene transcription requires S6K1 and is mediated by phosphorylation of the carboxy-terminal activation domain of the nucleolar transcription factor UBF. Mol. Cell Biol. 2003, 23, 8862-8877. [CrossRef] 
24. Hara, K.; Yonezawa, K.; Kozlowski, M.T.; Sugimoto, T.; Andrabi, K.; Weng, Q.P.; Kasuga, M.; Nishimoto, I.; Avruch, J. Regulation of eIF-4E BP1 phosphorylation by mTOR. J. Biol. Chem. 1997, 272, 26457-26463. [CrossRef]

25. Chuprin, A.; Gal, H.; Biron-Shental, T.; Biran, A.; Amiel, A.; Rozenblatt, S.; Krizhanovsky, V. Cell fusion induced by ERVWE1 or measles virus causes cellular senescence. Genes Dev. 2013, 27, 2356-2366. [CrossRef]

26. Cox, L.S.; Redman, C. The role of cellular senescence in ageing of the placenta. Placenta 2017, 52, 139-145. [CrossRef] [PubMed]

27. Londero, A.P.; Orsaria, M.; Marzinotto, S.; Grassi, T.; Fruscalzo, A.; Calcagno, A.; Bertozzi, S.; Nardini, N.; Stella, E.; Lelle, R.J.; et al. Placental aging and oxidation damage in a tissue micro-array model: An immunohistochemistry study. Histochem. Cell Biol. 2016, 146, 191-204. [CrossRef] [PubMed]

28. Sukenik-Halevy, R.; Amiel, A.; Kidron, D.; Liberman, M.; Ganor-Paz, Y.; Biron-Shental, T. Telomere homeostasis in trophoblasts and in cord blood cells from pregnancies complicated with preeclampsia. Am. J. Obstet Gynecol. 2016, 214, 283.e1-283.e7. [CrossRef]

29. Biron-Shental, T.; Kidron, D.; Sukenik-Halevy, R.; Goldberg-Bittman, L.; Sharony, R.; Fejgin, M.D.; Amiel, A. TERC telomerase subunit gene copy number in placentas from pregnancies complicated with intrauterine growth restriction. Early Hum. Dev. 2011, 87, 73-75. [CrossRef] [PubMed]

30. Biron-Shental, T.; Sukenik-Halevy, R.; Sharon, Y.; Goldberg-Bittman, L.; Kidron, D.; Fejgin, M.D.; Amiel, A. Short telomeres may play a role in placental dysfunction in preeclampsia and intrauterine growth restriction. Am. J. Obstet. Gynecol. 2010, 202, 381.e1-381.e7. [CrossRef]

31. Biron-Shental, T.; Sukenik-Halevy, R.; Sharon, Y.; Laish, I.; Fejgin, M.D.; Amiel, A. Telomere shortening in intra uterine growth restriction placentas. Early Hum. Dev. 2014, 90, 465-469. [CrossRef]

32. Levine, R.J.; Maynard, S.E.; Qian, C.; Lim, K.H.; England, L.J.; Yu, K.F.; Schisterman, E.F.; Thadhani, R.; Sachs, B.P.; Epstein, F.H.; et al. Circulating angiogenic factors and the risk of preeclampsia. N. Engl. J. Med. 2004, 350, 672-683. [CrossRef]

33. Redman, C.W.; Staff, A.C. Preeclampsia, biomarkers, syncytiotrophoblast stress, and placental capacity. Am. J. Obstet. Gynecol. 2015, 213 (Suppl. 4), S9-S11. [CrossRef]

34. Redman, C.W.; Sargent, I.L.; Staff, A.C. IFPA Senior Award Lecture: Making sense of pre-eclampsia-two placental causes of preeclampsia? Placenta 2014, 35, S20-S25. [CrossRef] [PubMed]

35. ACOG. Definition of Term Pregnancy, Committee Opinion No. 579; ACOG: New Orleans, LA, USA, 2013; pp. 1139-1140.

36. Brown, M.A.; Lindheimer, M.D.; de Swiet, M.; Van Assche, A.; Moutquin, J.M. The classification and diagnosis of the hypertensive disorders of pregnancy: Statement from the International Society for the Study of Hypertension in Pregnancy (ISSHP). Hypertens Pregnancy 2001, 20, IX-XIV. [CrossRef] [PubMed]

37. Mistry, H.D.; Wilson, V.; Ramsay, M.M.; Symonds, M.E.; Broughton Pipkin, F. Reduced selenium concentrations and glutathione peroxidase activity in pre-eclamptic pregnancies. Hypertension 2008, 52, 881-888. [CrossRef] [PubMed]

38. Mistry, H.D.; McCallum, L.A.; Kurlak, L.O.; Greenwood, I.A.; Broughton Pipkin, F.; Tribe, R.M. Novel expression and regulation of voltage-dependent potassium channels in placentas from women with preeclampsia. Hypertension 2011, 58, 497-504. [CrossRef]

39. Murthi, P.; Fitzpatrick, E.; Borg, A.J.; Donath, S.; Brennecke, S.P.; Kalionis, B. GAPDH, $18 \mathrm{~S}$ rRNA and YWHAZ are suitable endogenous reference genes for relative gene expression studies in placental tissues from human idiopathic fetal growth restriction. Placenta 2008, 29, 798-801. [CrossRef] [PubMed] 